to paralyse the vermiform mavements of the epigastric muscle-fibres, and prolong the sickness by intensifying the stagnation (which of itself induces nausea) of masses of food in the stomach, more successfully than alkalies and sedatives. If, for such a line of treatment, the sharp saline essences of pepsine and pancreatine be substituted, and given in largish doses (3iii to 3vi) neat, if food be in the 'stomach; or with concentrated food small in bulk, if vomiting have relieved the stomach of all its contents to the point of producing regurgitation and upthrowing of bilestained mucus; the retching will be rapidly quieted, and the stomach stimulated to contraction and due rotation of the food, in the most satisfactory manner.

Likewise in those forms of gastric and duodenal catarrhs, with sick headache, often styled "biliousness", the acid and saline essences of pepsine and pancreatine are markedly beneficial. The great feature of such cases is the large quantity of glairy mucus poured out by the membranes, which, since it opposes a barrier to osmosis, more especially prevents the absorption of sugar. An abnormal amount of what is formed passes into the duodenum; whereas, in healthy digestion, most of the sugar is at once taken up by the clean membrane of the œsophagus and lesser curve of the stomach. In these catarrhal states, acidulous saline essence of pancreatine is of sigtal service; the unaltered starch and unabsorbed sugar are prevented, apparently, from undergoing acetous fermentation, the outflow of mucus is lessened, and the passage of the contents of the stomach through the pylorus is expedited. This seems a much more rational treatment than the administration of soda with astringent bitters, since it does delay in any degree the chymification of the gravy soups and savoury albuminous fluids, which in such cases are generally the first aliments to sit easily on the epigastric mucous membrane.

The report prepared for me by Mr. G. Brownen is as follows. Its merits speak for themselves, and show, as I venture to think, that the speculations in which I have indulged, as to the way in which the saline essences may act when taken into the stomach, are not altogether unwarranted, even though future and more perfect investigation should tend to establish their comparative falsity.

[To be continued.]

\section{THE TREATMENT OF OZÆNA.}

\section{By W. PUGIN THORNTON, M.R.C.S.Eng.,} Surgeon to the St. Marylebone General Dispensary.

MUCH having been said lately on the treatment of ozæna, I herewith send notes of some consecutive cases, all of which have been treated with a nasal spray, and with a fairly successful result, judging from the time that has eliapsed since they were under my treatment. Had cases III and $\mathrm{v}$ been able to devote more time to treatment, the result in each case would have been, I feel convinced, speaking from late experience, entirely satisfactory. The spray consists of the following :

R Sodæ carbonatis, sôdæ biboratis, āa $3 \mathrm{jij}$; liquoris sodæ chlorinatæ 3ss-3ii; glycerini $3 \mathrm{j}$; aquam ad $\zeta_{\text {viij. }}$.

It is applied cold by means of a hand-ball spray-apparatus.

CASE I. - In the spring of 1877 , a Sister of Mercy consulted me in reference to great pain about the bridge of the nose and down the left side, extending over the cheek. The left eye also had become weak. There was much throbbing in the nostrils, and a burning sensation as though a gathering were forming, but which did not take place; and the nose became so tender that a handkerchief could not be used. Whenever the Sister was fatigued, or had been exposed to cold winds, the pain in the nostrils increased to such an extent as to keep he awake through the night. Often there was bleeding from the nose, and occasionally a clear fluid without smell would pass. The skin the bridge and sides of the nose was always of a bright red colour, which was, more noticeable when the internal discomfort was greater. She had been ordered an application to the throat, and, amongst other remedies, to sniff powdered borax up the nose. This organif condition had lasted for over two years. From March 1877 to the end of June, she was more or less under my care, and the only remedy I employed was the spray above mentioned. From that time to the present, there has been no return of the disorder, the redness of the skin has disappeared, nor has the Sister suffered from any inconvenience in her nose.

CASE II.-Miss -, aged 19, had scarlet fever in 1872. From that time she was subject to an offensive discharge, so copious that it saturated three or four handkerchiefs a day; at the same time, she suffered from deafness. This discharge was most severe during wet weather, less so during the summer months, especially if she were by the seaside, when it sometimes disappeared altogether. For two years, she had used inhalations of camphor, benzoin, etc., alternating with nasal douches containing permanganate of potash, carbolic acid, salt, and other ingredients. During this treatment, the deafness left her; but the discharge still continued. She visited me at first daily, then every other day, from November 26th to December 20th, 1877. I saw her again eleven times during January and February of 1878 . From that time till now, the discharge has ceased.

CASE III.-Mr. - was operated upon eighteen years ago for a polypus in the left nostril, a piece of bone coming away with the polypus. A tow-tent dipped in a "caustic solution" was carried in the nostril for some weeks after the operation. Two years after this treatment, Mr. - complained of much inconvenience in both nostrils, and a discharge commenced. The interior of the nose became painful, especially in that part whence the bone had been removed. "Casts" of mucus formed in the nostril, remaining about three days in damp, and a week in dry weather. The pain was great when these casts came away, keeping Mr. - awake throughout the night. A breath of air even would increase the discomfort much, so that (to use his own words) he was afraid to breathe through his nostrils. The discharge had a disagreeable smell, and blood was occasionally noticed in it. Mr. - had consulted, amongst others, M. Ricord, though he had never contracted syphilis, and had tried many remedies. I treated him daily from the 22nd of March, 1878, to the 3 Ist with the spray alone, and again from the $4^{\text {th }}$ to the IIth of April. His condition then improved, and the discharge ceased. A feeling of discomfort still remains in the upper part of the left nostril, but in a much less degree than formerly; and for this the spray is occasionally used. He finds benefit from passing the summer by the seaside, and from drawing up the salt water into his nostrils when bathing.

CASE IV.-Henry - a sailor, aged 30 , was a patient at the St. Marylebone General Dispensary in January 1878. He stated that early in the autumn of 1877 he had a severe pain over the right eye, lasting some days. This pain was followed by a discharge from the nostrils, offensive, and occasionally tinged with blood. On January 23 rd, he came to the Dispensary, and was ordered to use daily a nasal douche containing permanganate of potash, and to take iodide of potassium with liquor hydrargyri perchloridi three times a day. This treatment was carried out till February 25 th, when, little improvement having taken place, the spray was substituted for the douche, and he was given green iodide pills in the place of the mixture. He continued this treatment until April 3rd, when he was discharged, his nose being cured. He was told to continue taking the pills whilst at sea.

CASE V. - Mr. - a Swedish gentleman, aged 28, suffered from ozæna since his childhood. The discharge was offensive, and sufficient to saturate two or three pocket-handkerchiefs a day. It was the same in summer as in winter, but in cold damp weather it increased. After meals, the desire to clear the nostrils was always greater than at other times. He did not remember having ever been free from treatment. From 1870 to 1872 , he was twice a week, and hardly without intermission, seen by a Swedish physician, who used sprays, inhalations, and made applications to the interior of the nose with a brush, but without procuring any amelioration in his patient's condition. $\mathrm{Mr}$. - came to me first on February 27 th, 1877 , visiting me every other day to the 6 th April. He was, at the end of that time, free from the discharge, but there remained a feeling of tenderness in the nostrils. In November he returned, informing me that when the warm weather ceased he had a partial return of the discharge. After eight applications of the spray, the discharge almost ceased, and, as he could no longer remain under my immediate care, I ordered him to carry out a plan of treatment at his home. On April 2nd, 1878, Mr. - again called upon me. The discharge was slightly present, but without any smell accompanying it. After ten applications, he ceased coming, being almost cured, except that the feeling of tenderness remained to a slight extent. Some months ago, he paid me a visit; the ozænic condition being hardly appreciable.

CASE vi.-A clerk in the General. Post Office, five or six years ago, caught an ordinary cold, and from that time the discharge never disappeared. The interior of his nose used to feel half closed, and was very irritable in windy weather. Passing from a hot to a cold temperature brought on an attack of sneezing, as many as twenty fits of sneezing occurring without intermission. On waking in the morning, this patient began to sneeze; and never for some years had a day passed, whether in summer or winter, without this occurring. On one occasion, during warm weather, to show how readily an attack was brought on, he was standing over a grating looking into a shop window, when a current of cold air came up through the grating, and he then immediately sneezed twenty times. After these attacks, the discharge for a short time was increased, and often became thick and of a yellow colour. Traces of blood were sometimes to be found in it; but there 
was never any sriell noticed: At the commencement : of 1876 , he attended.St. Mary's Haspital, and for some :months was given iodide of potassium, as he trad contracted a chancre fifteen years previously. He had never since the : sore been ' affected with inyrisecondary symptoms. This treatment gave him no relief. In the eariy part of the winter of

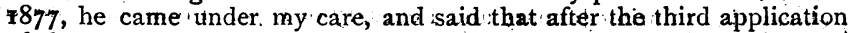
of the spray he began to feel better. The spray was continued: for over two months, the patient attending two or three times a week, no interrial remedies being given. Since'then there has been no return of the discharge, or any recurrence of the attacks of sneezing.

REMARKS. - These cases are, with one exception, all typical cases of simple ozæna. They presented most of the common symptoms of the complaint, which are : congestion of the mucous membrane with, commonly, slight thickening ; crustations of :dried mucus blocking up the'nostrils, which, on being removed, discover ulceration of the mucous surface, and occasionally destruction of bone; a constant discharge, either scanty or copious, thin or thick; perhaps mixed with blood, and frequently so offensive that : the i sufferer is debarred from society; a ranning of the discharge, when the patient is lying down, into the tarynx. In two cases in which the patients have suffered from chronic laryngitis previous to incurring ozena, the irritation caused by this gravitation of the nasal discharge has materially helped, it would seenr; to keep up the laryngeal congestion. Pain in or about the nostrils, or a feeling of discomfort, isevere enongh to keep the patient awake at night; redness of the skin over the bridge of the nose; the eyes or eyesight are in some cases affected. During the catamenial period the symptoms are with many increased. This ozenic condition causes a great depression of spirits, and with some patients a disgust for life, insomuch that they have often confessed to feeling inclined to commit suicide, and thus free themselves from what seemed to be an incurable disease.

I have inserted one syphilitic case, for the sprays appear to assist the constitutional remedies. This has been made evident in the case of a gentleman who came to me for ulceration in the right nostril, the result of primary disease contracted ten years :ago... It seems to me that in these cases of specific disease it is better to employ mercury rather than iodide of potassium, on account of the common tendency of the latter trug to cause a nasal discharge, at any rate to give it as isparingly as possible. A clergyman, who was under my care last year, after he had been cured of ozena took iodide of potassium for sciatica. At the end of a fortnight he had all his ozænic troubles back, and as they did not leave him after remission of the drug he was obliged to return for the spray-treatment.

\section{A NEW ANTISEPTIC DRESSING.}

\section{By HERBERT L. SNOW, M.D.Lond., Bayswater.}

IN the Journal for February 28 th, occurs a memorandum by SurgeonMajor MacNamara, in which the question is asked, "What is the best stłostitute in military surgery for exact antiseptic dressing?" And lint, soaked in carbolic acid solution, then covered by a layer of cottonwool, is the substitute proposed. I. venture to suggest another, which I think will be found far superior to this, and which is, indeed, in some respects better than the ordinary Listerian applications for ordinary hospitat practice. The dressing to which I allude is called "antiseptic marine lint"; the packages I have seen bear the name of $T$. Westhorp, Falcon Worlts, West India Road, E. It is practically fine oakum, but differs from the tenax in ordinary: surgical use in being more oily, more tenacious, and more thoroughly saturated (to all appearance) with tarry principles.

My experience of it extends to nine or ten operation-cases, chiefly excisions of the breast. I have operated on those under the carbolic spray; have subsequently applied a layer of the "marine lint", moistened with carbolic solution (without any intervening protective), and two or three 'dry layers of the same over this; outside the whole, a piece of mackin. tosh and ordinary calico bandages. The cases were dressed again (always under the spray) on the third day; subsequently, at intervals of from five days to a week. All except one united without any suppuration, quite as cleanly and as rapidly as under the complete Listerian plan. In the exception (a case of excision of the breast for cancer), torsion had been used instead of the ordinary catgut ligatures; there was consequently a profuse serous oozing reaching the outer atmo'sphere; the mackintosh and amount of "marine lint" were not proportionately enlarged; and the method accordingly failed in preventing supparation, though subsequently good recovery took place.

For ordinary hospital purposes, this "'marine lint" has two advan tages over the Listerian gauze; the first is, that it acts much more completely as a sponge, soaking up and holding innocuous in its meshes a
Jarge quantity of discharge; the second, that it is very much cheaperthe expense being $2 \mathrm{~d}$. or $3 \mathrm{~d}$. per dressing, in comparison with from 1.8. 6d, to $2 \mathrm{~s}$. $6 \mathrm{~d}$, in the other case.

For military surgery, $I$ am confident that it will prove the best ready application hitherto devised. The sponge-like action is very valuable and, when applied on the battle-field to wounds, the large amount of tarry principle held in solution is amply sufficient to keep a wound aseptic for several days, even without the useful adjunct of carbolic solution to moisten the first dressings.

My experience of cotton-wool as a dressing for operation-cases is decidedly unfavourable. It filters the air, doubtless; but in practice the surface next the wound becomes "caked" by the discharge ; an impervious "skin" thus formed pens up the latter, and" frequent dressings are necessary, or bad consequences quickly follow.

In a dangerous and critical operation, it is a good plan to use Lister's method in its entirety for the first two or three dressings; subsequently, when the discharge has lessened, the "marine lint". I need hardly point out the advantages of this latter as a dressing for large burns in the suppurating stage, or as an application to foetid cancerous ulcers, etc.

So far, I am not disposed to trust this absorbent lint quite so implicitly as the carbolic gauze and protective; but it is far. cheaper, less complicated, and readier of application, and in the majority of ordinary operation-cases answers quite as well.

\section{ATTEMPTED SUICIDE BY STRYCHNIA, SUCCESS- FULLY TREATED BY HYDRATE OF CHLORAL.*}

\section{By GEORGE GRAY, M.D., Castlewellan, Co. Down.}

ON December 3oth, 1879, I was called upon to visit a man living about two miles and a half distant, who, the messenger informed me, had taken a poisonous dose of strychnia. When $I$ arrived at the house, about half-past twelve o'clock, I found the patient; a man 34 or 35 years of age, supported in bed in a semirecumbent position, with his head thrown back, his eyes staring, and evidently suffering from the usual symptoms of poisoning by strychnia. The muscular spasm came on with a tremor like a jerky kind of convulsion, and recurred about every three minutes. During the spasm, the breathing was irregular, and the breath came through the closely clenched teeth with a hissing sound. The angles of the mouth were drawn down, and the peculiar Sardonic grin well marked; the skin was cold, and covered with a clammy perspiration. The pulse was very weak and quick, but not irregular. During the intervals between the convulsive attacks, the spasm of the jaw did not pass off, and any attempt to open the mouth forcibly at once brought on a fresh attack, which was preceded by a peculiar sound -half groan, half cry.

Having brought with me a solution of two drachms of hydrate of chloral in two ounces of water, I poured half of it into a cup, and managed slowly to administer it with a teaspoon by inserting the point of the latter in a space where he had lost two molar teeth, and directing him to suck in the fluid. This he did in the intervals of the attacks, swallowing it with a gulp until the ounce of fluid was taken. After swallowing the chloral, he had only two severe spasms, the latter less marked than the former; and, at gradually lengthening intervals, they became less severe. In ten minutes, the jaw was so relaxed that I thought I could introduce the tube of a stomach-pump, but as doing so seemed to cause great distress and increased the jerking of the muscles, I did not persevere, but gave him an emetic of thirty grains of sulphate of zinc and warm water, and when this had acted I gave him a drachm of tannin; this he vomited also.

After waiting for an hout, as there were now and then slight tremors in some of the muscles, as no doubt some of the chloral was removed by the emetic, and as there was not any drowsiness, I gave half what remained of the solution - that is, half a drachm of chloral-hydrate, and applied warmth to the skin. In another hour, he was so much improved that I left, giving directions that if he had any more twritching, or if he had not any drowsiness - which had not yet appeared-to give him in three hours the remainder of the draught, and to let: me hear of him in the evening. At seven o'clock, I heard that he had the chloral draught at five, but had not slept, and was feeling comfortable, having no more vomiting or convulsions. I ordered him a dose of castor-oil at bedtime.

There is nothing further to note of the progress of the case, as, two days afterwards, he was at his usual work.

On making inquiry, I found that, for a fortnight before, he had

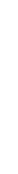

.

.

